\title{
BMJ Open Do smokers have greater risk of delayed and non-union after fracture, osteotomy and arthrodesis? A systematic review with meta-analysis
}

\author{
R G Pearson, R G E Clement, K L Edwards, B E Scammell
}

To cite: Pearson RG, Clement RGE, Edwards KL, et al. Do smokers have greater risk of delayed and non-union after fracture, osteotomy and arthrodesis? A systematic review with meta-analysis. BMJ Open 2016;6: 010303 .

doi:10.1136/bmjopen-2015010303

- Prepublication history and additional material is available. To view please visit the journal (http://dx.doi.org/ 10.1136/bmjopen-2015010303)

Received 20 October 2015 Revised 21 September 2016 Accepted 29 September 2016

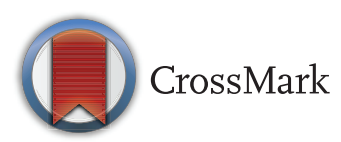

Division of Rheumatology, Orthopaedics and Dermatology, School of Medicine, University of Nottingham, Queen's Medical Centre, Nottingham, UK

Correspondence to Dr R G Pearson; richard. pearson@nottingham.ac.uk

\section{ABSTRACT}

Objectives: Systematic review and meta-analysis of published observational cohort studies. To quantify the increased risk smokers have of experiencing a delayed and/or non-union in fractures, spinal fusion, osteotomy, arthrodesis or established non-unions. Setting: Medical Literature Analysis and Retrieval System Online (MEDLINE), Excerpta Medica database (EMBASE), Allied and Complementary Medicine Database (AMED) and Web of Science Core Collection from 1966 to 2015.

\section{Study eligibility criteria, participants and} interventions: Observational cohort studies that reported adult smokers and non-smokers with delayed and/or non-union or time to union of the fracture, spinal fusion, osteotomy, arthrodesis or established non-union were eligible.

\section{Data extraction and outcome measures:}

2 authors screen titles, abstracts and full papers. Data were extracted by 1 author and checked independently by a second. The relative risk ratios of smoking versus nonsmoking and the mean difference in time to union patients developing a delayed and/or non-union were calculated.

Results: The search identified 3013 articles; of which, 40 studies were included. The meta-analysis of 7516 procedures revealed that smoking is linked to an increased risk of delayed and/or non-union. When considered collectively, smokers have 2.2 (1.9 to 2.6) times the risk of experiencing delayed and/or non-union. In all the subgroups, the increased risk was always $\geq 1.6$ times that of non-smokers. In the patients where union did occur, it was a longer process in the smokers. The data from 923 procedures were included and revealed an increase in time to union of 27.7 days (14.2 to 41.3 ).

\section{Conclusions: Smokers have twice the risk of} experiencing a non-union after fracture, spinal fusion, osteotomy, arthrodesis or treatment of non-union. Time to union following fracture, osteotomy, arthrodesis or treatment of an established non-union is longer in smokers. Smokers should be encouraged to abstain from smoking to improve the outcome of these orthopaedic treatments.

\section{INTRODUCTION}

The incidence of fractures in England is reported to be as high as $3.6 \%$ with over a third of the population sustaining at least

\section{Strengths and limitations of this study}

- This is a comprehensive systematic review of the published literature, including 40 studies achieving a large sample size of over 8000 adults.

- This meta-analysis identifies that smokers take 27.7 days (14.2 to 41.3 ) longer for union to occur and smokers have double the risk of nonunion 2.2 (1.9 to 2.6).

- Included data originated from observational cohort studies as randomised controlled trials (RCTs) are not available addressing this topic. The feasibility of conducting RCTs with patients being randomly allocated to continuing smoking or smoking cessation is faced with many ethical issues and potential biasing. The quality of included studies as defined by the Meta-Analyses and Systematic Reviews of Observational Studies (MOOSE) guidelines was variable and notably often did not adjust for baseline differences. Similarly, included studies often did not thoroughly investigate potential confounders such as alcohol consumption.

one fracture in their lifetime. ${ }^{1}$ The majority of fractures heal uneventfully, but those that ultimately fail to unite have wide-ranging implications for the patient and are a huge financial burden on the healthcare service. The cost of non-union in a tibia shaft fracture can be upwards of $£ 10000$. $^{2}$

A number of clinical factors are known to be deleterious to fracture healing, including the fracture classification severity, advancing age, infection, the use of non-steroidal antiinflammatory drugs and corticosteroids and smoking. ${ }^{3}$ Despite the considerable morbidity and mortality associated with smoking, it is estimated that $19 \%$ of the adult UK population continues to smoke. ${ }^{4}$ Smoking is therefore an important modifiable factor associated with delayed healing of fracture and allied orthopaedic procedures.

This research focuses on the systematic review and meta-analysis of observational 
cohort studies. These were considered collectively but also as subgroups based on the injury or the treatment. The subgroups for the delayed and/or non-union in smokers and non-smokers were long bone fracture, ${ }^{5-18}$ spinal fusions, ${ }^{19-24}$ osteotomy, ${ }^{25-29}$ arthrodesis ${ }^{30-37}$ and established non-union. ${ }^{23}{ }^{38-42}$ The mean difference in the time to union between smokers and non-smokers was also subjected to meta-analysis. ${ }^{5} 7131426274344$

There have been a large number of observational studies investigating the effect of smoking on bone healing, and these have been summarised in a number of recent review articles. ${ }^{45-50}$ The objective of this review was to identify if there is an increase in delayed and/or non-union in smokers compared with non-smokers and if this is the case to quantify this as risk ratios. In addition, we quantified the mean difference in the time to union between smokers and non-smokers. Hence, we are able to provide evidence-based information on the difference in risk of developing a non-union or the time taken for union to occur in smokers.

\section{METHODS}

We followed the Preferred Reporting Items for Systematic Reviews and Meta-Analyses (PRISMA) guidelines in conducting a systematic review of the literature (research checklist 1). In reporting our meta-analysis, we followed the guidance provided by MOOSE; proposals for reporting meta-analysis of observational studies (research checklist 2). ${ }^{51}$

\section{Data sources and search strategy}

A literature search was conducted through MEDLINE, EMBASE, AMED, Web of Science Core Collection from 1966 to May 2015 using the keywords 'smoking', 'nicotine', 'fracture', 'arthrodesis' (and the alternative spelling 'arthrodeses') and osteotomy as subject headings and abstract, using the search string (smoking OR nicotine) AND (fracture OR arthrodesis OR arthrodeses OR osteotomy). Non-English language articles were included. An example of a detailed search strategy for Web of Science is provided (see online supplementary file 1). The search results were exported to an Endnote database. Duplicates were deleted leaving us with the potentially relevant studies. We narrowed down the papers through a staged process. In stage 1 , we reviewed the titles and if the title indicated likelihood that the article might meet the eligibility criteria, we retrieved the abstract. In stage 2 , we reviewed the abstracts and selected potentially eligible studies for retrieval of the full text. In stage 3, we checked the full-text publication against the eligibility criteria. Finally, we reviewed the bibliography of each study that met our inclusion criteria for additional studies. Conference abstracts were excluded.

\section{Study selection}

Inclusion criteria

We identified studies presenting data which enabled the calculation of the risk ratio of delayed and/or non-union between smokers and non-smokers. Similarly, through systematic review, we identified observational cohort studies reporting or providing raw data which enabled the calculation of the mean difference in time to union between smokers and non-smokers. Only peerreviewed published literature of adults who had fractured a bone or who had undergone a spinal fusion, osteotomy or arthrodesis or treatment of an established non-union was included. Occasionally, instances arose where a small amount of additional data was required to include the study and the corresponding author was contacted. Where data were forthcoming in a personal communication, the study was included.

\section{Exclusion criteria}

Papers that did not make a direct comparison between smokers and non-smokers were excluded. Limb distraction studies were not included unless this was conducted as a combined procedure with arthrodesis.

\section{Data extraction and quality assessment}

Data extraction was independently performed by two authors (RGP, RGEC). The following data were extracted from each paper: author's name, publication year, study design, patient demographics, definition of smoker, fracture/procedure type, definition of union and nonunion, length of follow-up, loss to follow-up, time to fracture union, number of patients included in the study and number experiencing delayed and/or non-union. The subgroup meta-analysis was conducted on fractures, spinal fusion, osteotomy, arthrodesis and established non-union were recorded.

The quality of each selected study was assessed with the Newcastle-Ottawa Scale (NOS) for assessing the quality of non-randomised studies in meta-analyses. ${ }^{52}$ This checklist was applied to make an assessment covering three broad perspectives: the selection of the study groups; the comparability of the groups; and the ascertainment of either the exposure or outcome of interest in each observational cohort study. The studies are graded 0-9 with higher scores indicating higher quality studies. $\kappa$ analysis was performed to assess agreement between the quality raters.

\section{Data synthesis and analysis}

For statistical analysis and the preparation of figures, several software packages were used; IBM SPSS Statistics V.20, StatsDirect statistical software V.2.8 and Review Manager (RevMan) software, V.5.3 (Copenhagen: The Nordic Cochrane Centre, The Cochrane Collaboration, 2012) were used. Raw data for non-union events and time to union from each study were entered and used to calculate a relative risk (RR) or mean difference for each study. The subtotal and total pooled risk ratios were obtained using a random effects model based on estimating the amount of between-study variation by comparing each study's result with a Mantel-Haenszel fixed-effect meta-analysis result. The subgroups of 
fractures, spinal fusion, osteotomy, arthrodesis and established non-union were identified. The analysis also attributed a weight to each study defined by inverse variance. Forest plots were used to express risk ratios or mean differences with $95 \%$ CI for each study. Hence, the main outcome measures were the risk ratio between smokers and non-smokers in the development of delayed union and/or non-union. The mean difference in the time to union between smokers and non-smokers was also determined.

\section{Heterogeneity between studies and assessment of meta-analysis bias}

The Cochrane $\mathrm{Q}$ and the $\mathrm{I}^{2}$ statistics were used to assess study heterogeneity. Bias was initially assessed by funnel plot asymmetry. The data were also subjected to Egger analysis. Where bias was identified through this methodology, it was investigated further, considering parameters such as size of study, bone site or confounders such as diabetes, excessive alcohol consumption, drug abuse or socioeconomic group. Calculation of Rosenthal's fail-safe number was considered as suggested in the MOOSE guidelines but was discounted due to the reasons reported in the Cochrane guidance on meta-analysis. ${ }^{53}$ Essentially, it has been reported that available calculation methods lead to diverse estimates of the number of additional studies required to bring the $\mathrm{p}$ value above 0.05 . The method also runs against the principle that in medical systematic reviews, the focus is on effect size and CI of the estimated observed effect as opposed to the $p$ value reaching an arbitrary value.

\section{RESULTS}

Identification of studies

The search identified 1164 articles in MEDLINE, 2613 in EMBASE, 35 in AMED and 1991 in Web of Science Core Collection at stage 1. At stage 2, duplicates were deleted leaving 3013 potentially relevant publications. At stage 3 , selection was made from the 3013 based on the titles, which identified 396 publications. At stage 4, selection was based on reading the abstracts, giving a total of 101 publications. At stage 5, from studying the 101 fulltext publications, and 46 study citation arising from these manuscripts (15 of which were included), a total of 40 studies were included and used for the meta-analysis (figure 1 ).

\section{Characteristics of included studies}

Of the 3013 publications, we extracted data from 40 studies that met our eligibility criteria (see online supplementary file 2). These studies had been conducted in a broad range of clinical settings, ranging from provincial clinics to level 1 trauma centres within university teaching hospitals, with some studies being multicentre. The range of nations where the research originated was diverse, including the Netherlands, Finland, Australia, Sweden, USA, Germany, Denmark,
West Indies, China, Belgium, Greece, Turkey, Italy, Canada and the UK. Classification of the extent a smoker smoked was broad across of the range of studies which meant that it was only possible to classify participants into smokers and non-smokers for the meta-analysis. Exclusion of studies from the meta-analysis covered both types of case-control studies, each with their own complexities. Those where the case was smoking ${ }^{54}$ and those where the case was non-union. ${ }^{56-59}$ Within the included studies, there were retrospective and prospective observational cohort studies, with the majority being retrospective. This often gave rise to confusion regarding the reporting of exclusion criteria and loss to follow-up. Many studies chose to exclude patients due to a combination of reasons with those being excluded on the basis of a lack of suitable follow-up not being specifically identified. Inconsistent definition of delayed and non-union was prevalent in the studies with several grouping their defined definition of delayed with their definition of non-union. Hence, we reached the decision not to discriminate between delayed and non-union in the meta-analysis. In general, the follow-up was for a sufficient length of time and numbers lost $<20 \%$; however, on occasion, this information was not reported. The definition of union tended to be a combination of radiological and clinical factors, often based on weightbearing capacity of a lower limb. Radiological union criteria tended to be described as bridging of at least three of the four bone cortices. Comorbidities were mentioned in a number of studies; however, it was rare to identify an approach to combat such confounders using multivariate analysis. The quality of the eligible studies was broad and often lacking in detail, which made assessment of the quality using the NOS difficult to apply (see online supplementary file 2 ). This was highlighted by the $\kappa$ analysis indicating relatively poor agreement, $\kappa=0.18$ (0.05 to 0.31$)$ and weighted $\kappa 0.24$ (0.09 to $0.39)$.

\section{Delayed and/or non-union and time to union}

The analysis of the data reveals that smokers have a greater risk of incidence of delayed and/or non-union. This is presented as risk ratios in the forest plot (figure 2). Thirty-eight studies were included. The patients underwent a broad range of orthopaedic treatments and procedures from fractures, spinal fusions, osteotomies, arthrodesis to treatment of established non-union. The meta-analysis of 7500 procedures revealed that smokers have an increased risk of delayed and/or non-union. When considered collectively, smokers have 2.2 (1.9 to 2.6) times the risk of experiencing delayed and/or nonunion. In all the subgroups, the increased risk was always $\geq 1.6$ times that of non-smokers.

Time to union was a longer process in smokers as identified in the eight studies included in the mean difference to union meta-analysis. Six of these studies also provided data for the RR meta-analysis. Figure 3 shows that the bones of smokers take longer to unite following 
Figure 1 PRISMA flow diagram describing numbers of included and excluded studies at the and reviewing the literature. progressive stages of searching

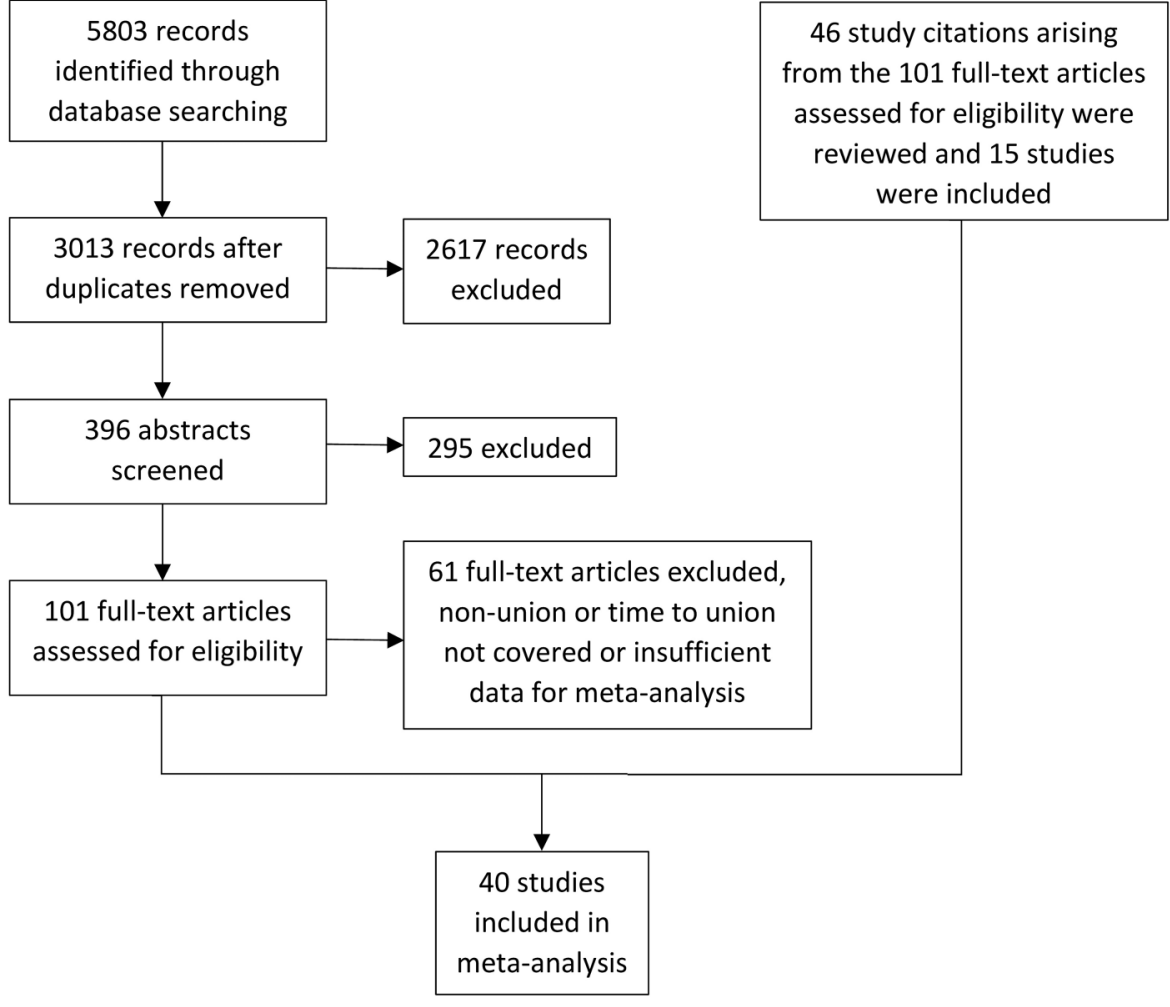

tibia fractures, including when treated with an externalfixator; or tibial osteotomies, or established non-union of the tibia. This was also identified when treating hallux valgus with an osteotomy or arthrodesis. The data from 923 procedures revealed it took an additional 27.7 days (14.2 to 41.3) for union to occur in smokers.

\section{Heterogeneity and bias}

Considering all the included studies as one group with $\mathrm{df}=37$ in the delayed and/or non-union data, there is moderate heterogeneity, with an $\mathrm{I}^{2}$ value of $47 \%$. This heterogeneity was further investigated, the majority of the diversity originating from studies where the number of events, that is, delayed and or non-union, were small and in particular where there was a zero value in one of the exposures, usually non-smokers. Cochrane RevMan software assigns a very small value to enable the risk ratio to be calculated. It is worth noting that this then results in the large risk ratio estimates being made, with large CIs. When there are a large number of studies in the subgroup, heterogeneity is not observed within that subgroup, with $\mathrm{I}^{2}$ values of $0 \%$ as seen in the fractures subgroup 1.7 (1.4 to 2.0). There were fewer studies in each of the remaining subgroups, however in spinal fusions 1.6 (1.3 to 2.1), osteotomy 2.9 (1.9 to 4.4) and arthrodesis 3.0 (2.1 to 4.3 ) no heterogeneity was identified, $\mathrm{I}^{2}$ equal to $0 \%$. In the treatment of the established non-union subgroup $11.8(0.8,178.8), \mathrm{I}^{2}$ was equal to 23\%. This heterogeneity can be attributed to the Hak et al study, ${ }^{38}$ a relatively small study that did not identify any non-unions after surgical treatment of the non-smoking patients. All of these three procedures are linked to a higher risk ratio. It could be considered that arthrodesis and treatment of non-union are likely to be linked to comorbidities which impact on bone biology and hence the increased risk of incidence of non-union in smokers. Alternatively, these procedures are less likely to result in a non-union in non-smokers which could increase the risk ratio with smokers. The heterogeneity between the subgroups is considerable and is supported by an $\mathrm{I}^{2}$ of $84 \%$, clearly being attributable to the difference between the fractures/spinal fusion subgroups and osteotomy, arthrodesis and treatment of non-union.

When considering the bias across the studies within the non-union analysis, there was little identified, exemplified in the SE- $\log \mathrm{RR}$ funnel plot, the majority of studies lying within the demarcated funnel (figure 4). However, when considering the bias among the time to union studies, it is evident that those studies with larger SE tended to be the studies which identified the largest effect size between the smokers and non-smokers.

\section{DISCUSSION}

Smokers have poor bone healing. The meta-analysis reveals that smokers have a greater risk of incidence of delayed and/or non-union. This is the case for a broad range of orthopaedic treatments and procedures from fractures, spinal fusions, osteotomies, arthrodesis to established non-union. This meta-analysis assessed a total of 7516 procedures. When considered collectively, smokers have 2.2 (1.9 to 2.6) times the risk of experiencing delayed and/or non-union. In all the subgroups, 
Smoking Non-smoking

Study or Subgroup 1.1.1 Fractures

Kyro 1993

Schmitz 1999

Adams 2001

Harvey 2002

McKee 2003

Castillo 2005

Ristiniemi 2007

Enninghorst 2011

Moghaddam 2011

Ahmad 2012

Ding 2014

Tay 2014

Liu 2015

Ruffolo 2015

Subtotal $(95 \% \mathrm{Cl})$

Total events

Heterogeneity: $\mathrm{Tau}^{2}=0.00 ; \mathrm{Chi}^{2}=12.97, \mathrm{df}=13(\mathrm{P}=0.45) ; \mathbf{I}^{2}=0 \%$

Test for overall effect: $Z=6.49(P<0.00001)$

1.1.2 Spinal Fusions

$\begin{array}{lrrrrr}\text { Martin 1999 } & 13 & 75 & 21 & 214 & 3.7 \% \\ \text { Glassman 2000 } & 39 & 188 & 24 & 169 & 4.8 \% \\ \text { Andersen 2001 } & 22 & 97 & 25 & 199 & 4.4 \% \\ \text { Hilibrand 2001 } & 21 & 55 & 25 & 135 & 4.6 \% \\ \text { Luszczyk 2013 } & 14 & 156 & 35 & 417 & 3.9 \% \\ \text { Subtotal (95\% Cl) } & & 571 & & 1134 & 21.4 \% \\ \text { Total events } & 109 & & 130 & & \end{array}$

Heterogeneity: $\mathrm{Tau}^{2}=0.00 ; \mathrm{Chi}^{2}=3.30, \mathrm{df}=4(\mathrm{P}=0.51) ; \mathrm{I}^{2}=0 \%$

Test for overall effect: $Z=3.98(P<0.0001)$

1.1.3 Osteotomy

W-Dahl 2004

W-Dahl 2007

Meidinger 2011

van Houten 2014

Subtotal $(95 \% \mathrm{CI})$

Total events

Heterogeneity: $\mathrm{Tau}^{2}=0.00 ; \mathrm{Chi}^{2}=1.23, \mathrm{df}=4(\mathrm{P}=0.87) ; \mathrm{I}^{2}=0 \%$

Test for overall effect: $Z=5.07(P<0.00001)$

1.1.4 Arthrodesis

Perlman 1999

Easley 2000

Ishikawa 2002

Chahal 2006

Collman 2006

Hamilton 2007

Fragomen 2012

Subtotal $(95 \% \mathrm{Cl})$

Total events

$\begin{array}{lllll}4 & 20 & 0 & 20 & 0.3 \%\end{array}$

$\begin{array}{llll}34 & 25 & 166 & 4.3 \%\end{array}$

$\begin{array}{llll}41 & 2 & 113 & 0.5 \%\end{array}$

$\begin{array}{llll}46 & 5 & 136 & 16 \%\end{array}$

$\begin{array}{llll}58 & 8 & 146 & 2.6 \%\end{array}$

199

$\begin{array}{ll}146 & 2.6 \% \\ \mathbf{5 8 1} & \mathbf{9 . 4} \%\end{array}$

Heterogeneity: $\mathrm{Tau}^{2}=0.00 ; \mathrm{Chi}^{2}=6.18, \mathrm{df}=7(\mathrm{P}=0.52) ; \mathrm{I}^{2}=0 \%$

Test for overall effect: $Z=5.82(P<0.00001)$

1.1.5 Non-union treatment

$\begin{array}{lrrrrr}\text { Hak 2000 } & 10 & 15 & 0 & 8 & 0.4 \% \\ \text { Chang 2006 } & 7 & 13 & 7 & 35 & 2.7 \% \\ \text { Little 2006 } & 13 & 30 & 4 & 34 & 2.1 \% \\ \text { Dinah 2007 } & 12 & 20 & 3 & 17 & 1.9 \% \\ \text { Assiotis 2012 } & 4 & 15 & 6 & 29 & 1.8 \% \\ \text { Murray 2013 } & 73 & 219 & 52 & 722 & 5.8 \% \\ \text { Subtotal (95\% CI) } & & 312 & & 845 & 14.8 \% \\ \text { Total events } & 119 & & 72 & & \end{array}$

Heterogeneity: $\mathrm{Tau}^{2}=0.06 ; \mathrm{Chi}^{2}=6.46, \mathrm{df}=5(\mathrm{P}=0.26) ; \mathrm{I}^{2}=23 \%$

Test for overall effect: $Z=6.38(P<0.00001)$

Total $(95 \% \mathrm{Cl})$

2430

$5026 \quad 100.0 \%$

Total events

602 526

Heterogeneity: $\mathrm{Tau}^{2}=0.11 ; \mathrm{Chi}^{2}=70.30, \mathrm{df}=37(\mathrm{P}=0.0008) ; \mathrm{I}^{2}=47 \%$

Test for overall effect: $Z=8.92(P<0.00001)$

Test for subaroup differences: $\mathrm{Chi}^{2}=24.12, \mathrm{df}=4(\mathrm{P}<0.0001), \mathrm{I}^{2}=83.4 \%$
Risk Ratio

Risk Ratio

M-H, Random, 95\% Cl

$1.57[1.03,2.42]$

$7.22[0.36,146.88]$

$1.32[0.91,1.93]$

$2.58[0.75,8.86]$

$4.15[0.97,17.82]$

$2.41[1.15,5.06]$

$2.71[1.02,7.20]$

$1.71[0.91,3.21]$

$16.17[0.97,269.23]$

$3.67[0.17,79.54]$

$2.53[1.16,5.55]$

$1.49[1.14,1.95]$

$1.90[1.28,2.82]$

$0.88[0.31,2.50]$

$1.67[1.43,1.95]$

$1.77[0.93,3.35]$

$1.46[0.92,2.32]$

$1.81[1.07,3.03]$

$2.06[1.27,3.36]$

$1.07[0.59,1.93]$

$1.62[1.28,2.05]$

$9.00[0.52,156.91]$

$2.73[1.59,4.69]$

$1.38[0.13,14.80]$

$2.96[0.90,9.75]$

$3.46[1.47,8.17]$

$2.93[1.93,4.44]$

$8.44[0.50,143.77]$

$1.46[0.63,3.37]$

$3.35[1.57,7.12]$

$2.63[1.02,6.80]$

$3.09[1.19,8.03]$

$1.70[0.33,8.82]$

$7.88[0.48,130.28]$

$5.25[2.30,12.01]$

$2.96[2.06,4.27]$

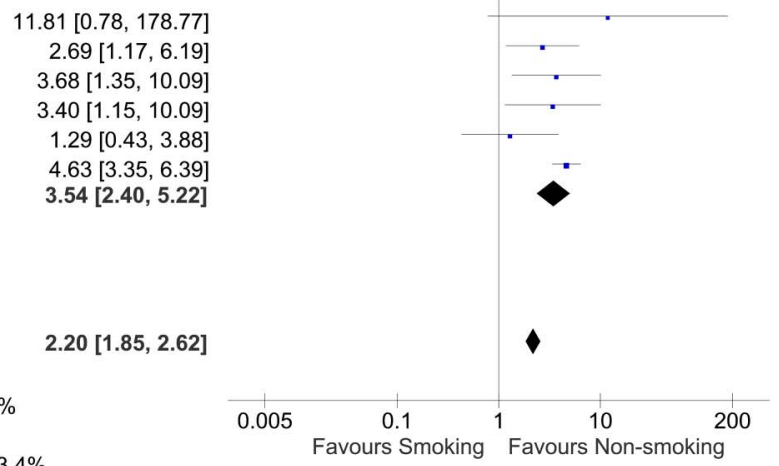

Figure 2 Delayed and non-union in smokers and non-smokers-fractures, spinal fusions, osteotomy, arthrodesis and treatment of established non-union. 


\begin{tabular}{|c|c|c|c|c|c|c|c|c|}
\hline \multirow[b]{2}{*}{ Study or Subgroup } & \multicolumn{3}{|c|}{ Smoking } & \multicolumn{3}{|c|}{ Non-smoking } & \multirow[b]{2}{*}{ Weight } & \multirow{2}{*}{$\begin{array}{l}\text { Mean Difference } \\
\text { IV, Random, } 95 \% \text { C }\end{array}$} \\
\hline & Mean & SD & Total & Mean & SD & Total & & \\
\hline Kyro 1993 & 166 & 92 & 71 & 134 & 71 & 64 & $12.5 \%$ & $32.00[4.42,59.58$ \\
\hline Adams 2001 & 226 & 118 & 140 & 194 & 113 & 133 & $12.6 \%$ & $32.00[4.60,59.40]$ \\
\hline W-Dahl 2004 & 110 & 25.2 & 34 & 94 & 18 & 166 & $23.3 \%$ & $16.00[7.10,24.90]$ \\
\hline Dujardyn 2007 & 228 & 79.1 & 16 & 173 & 60.8 & 12 & $5.4 \%$ & $55.00[3.18,106.82]$ \\
\hline W-Dahl 2007 & 100 & 25 & 41 & 93 & 14 & 113 & $23.7 \%$ & $7.00[-1.08,15.08$ \\
\hline Alemdaroglu 2009 & 192.78 & 81.263 & 13 & 149.59 & 35.553 & 19 & $6.3 \%$ & $43.19[-3.79,90.17$ \\
\hline Moghaddam 2011 & 122.01 & 78.68 & 46 & 83.44 & 30.52 & 39 & $13.9 \%$ & $38.57[13.90,63.24$ \\
\hline Ahmad 2012 & 247.33 & 102.37 & 6 & 110.6 & 28.36 & 10 & $2.4 \%$ & $136.73[52.95,220.51$ \\
\hline Total $(95 \% \mathrm{CI})$ & & & 367 & & & 556 & $100.0 \%$ & $27.71[14.16,41.2$ \\
\hline
\end{tabular}

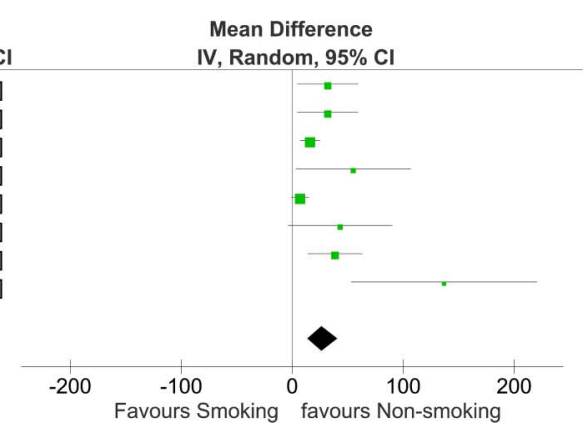

Figure 3 Time to union in smokers and non-smokers-fractures, spinal fusions, osteotomy, arthrodesis and treatment of established non-union.
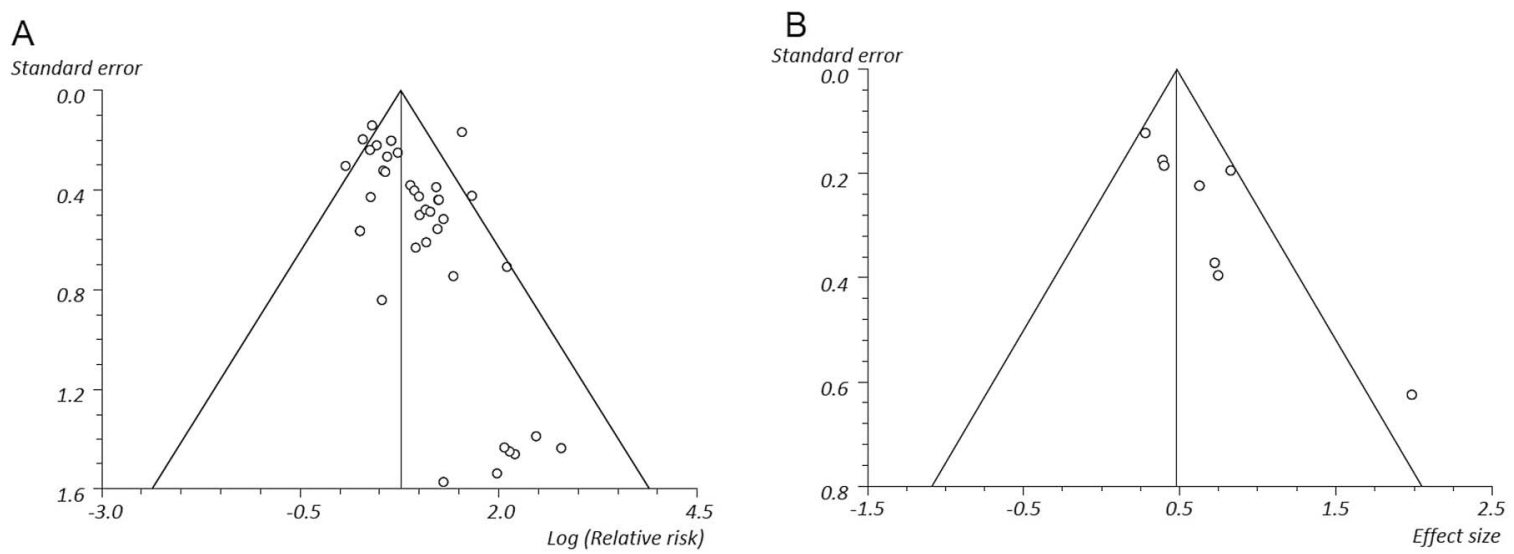

Figure 4 Bias funnel plots; (A) non-union log relative risk, (B) time to union effect size.

the increased risk was always $\geq 1.6$ times that of non-smokers.

The eight eligible time to union studies identified that union was a longer process in smokers and is reported as the mean difference in time to union in the meta-analysis. A total of 923 procedures comprised the data set and revealed time to union was 27.7 days (14.2 to 41.3) longer in smokers. Bones of smokers take longer to unite; following tibia fractures, tibial osteotomies or established non-union. This was also the case for osteotomy or arthrodesis used in the treatment of hallux valgus.

\section{Contribution of smoking and injury to healing}

Cigarette smoke contains in excess of 4800 constituents with at least 200 known to be toxic. It is well documented that smoking has an adverse effect on bone physiology, leading to decreased bone mineral density and increased incidence of osteoporotic fractures. ${ }^{60-62}$ The effect of smoking on fracture healing is considered to be multifactorial; physiological changes at the fracture site include hypoxia and modification of cellular metabolic activity. Nicotine is a powerful vasoconstrictor causing reduction in peripheral blood flow; carbon monoxide reduces the oxygen-carrying capacity of the blood through the formation of carboxyhaemoglobin and hydrogen cyanide inhibits cytochrome c oxidase preventing aerobic metabolism.

We hypothesise that a significant contribution to the deleterious effects of smoking is made through changes to the blood supply inducing hypoxia, implying the effect could be greater in severe fracture subtypes where oxygen delivery to the fracture site is most extensively compromised. The accelerated failure time model constructed by Kyro et a $a \tilde{l}$ implies that as age and injury severity increases, the effect of cigarette smoking becomes more important. This is supported by evidence from Schmitz et $a l^{b}$ who found healing times in smokers were 1.5 times longer than non-smokers following simple fractures but at least 2.5 times longer after complex fractures where the damage to the blood supply is likely to be more significant. Adams $e t a l^{7}$ showed a trend for increasing times to union in open tibia fractures from Gustilo grade I to IIIA, but the trend did not continue into IIIB subtypes. The effect of smoking is likely to be linked to smoking-related comorbidities, for example, chronic obstructive pulmonary disease. ${ }^{63-65}$ There are also considerations regarding secondhand smoke; research has established that there is a link with biomarkers of cardiovascular disease risk in passive smokers. ${ }^{66}$

An interesting question is whether smokers develop a larger zone of injury than non-smokers which could be 
mediated by hypoxia and hyperoxidant stress. We are aware that smoking increases free radical production and that a high yield of free radicals is produced when a bone fractures. ${ }^{67}$ Hyperoxidant stress may play a larger part in smokers following fracture where their natural antioxidant mechanisms are already depleted and could contribute to why smokers' bones healed more slowly. ${ }^{5}$

\section{Strengths and weaknesses}

This is a comprehensive systematic review of the published literature presenting data synthesised through meta-analysis. This review adds to the literature of smoking and non-union. To the best of our knowledge, Scolaro $e t a l^{48}$ is the only published systematic review on this topic which has implemented meta-analysis which addressed non-union in long bones OR 2.32 (1.76 to 3.06) with subgroup analysis of tibial fractures and open fractures as subgroup analysis; whereas here we report a broad grouping of orthopaedic procedures with subgroups of fractures, spinal fusions, osteotomy, arthrodesis and non-union. Hence, our research indicates that smoking impacts a broad range of elected orthopaedic surgical procedures in addition to primary long bone fracture treatment.

However, there was a wide range in quality of studies included in the analysis from which we have drawn our conclusions. There was on the whole very little information regarding how many cigarettes were being smoked and it is also of note that it was extremely rare for any biochemical confirmation of non-smoking status, that is, cotinine or carbon monoxide. ${ }^{68}$ Study quality, severity of fracture or surgical procedure, age of patients, bone involved and non-union definition were identified as potential sources of heterogeneity. We have noticed that in all the studies where surgery for non-union is discussed, the percentage of smokers requiring surgical intervention is always higher than the non-smokers, but none of these studies have ascertained a statistical significance for this association. ${ }^{5} 7{ }^{26}$ In the light of these reports, we should consider this as a potential source of bias which merits further investigation. An additional topic which warrants further investigation is the covariate in smokers of alcohol consumption.

\section{Comparison of our univariate analysis with published RR or $\mathrm{OR}$}

Some studies reported risk ratio, whereas others reported ORs along with the raw data we extracted for meta-analysis. In four publications, OR and RR had been generated using multivariate regression analysis as opposed to univariate methods With an aim to facilitate comparison between our univariate analysis, employed for our meta-analysis, and published ORs, we calculated OR in addition to RR in these instances (table 1).

Our OR and RR values tended to be similar or identical to published univariate values with the exception of Chang et $a l^{39}$ OR 5.4 (1.3 to 22.13) where there was a small discrepancy compared with our OR of 4.7 (1.2 to 18.4) (table 1). On investigation, the reason for this could not be identified.

The published multivariate models are likely to have been adjusted for baseline differences such as age and sex, and in some studies for comorbidities, for example, severity of fracture. Considering the published multivariate analysis, $\mathrm{W}$-Dahl and Toksvig-Larsen ${ }^{26}$ produced a similar RR using multiple regression analysis to our univariate value. However, in two publications where multivariate models had been constructed, the OR reported was approximately double our univariate value $;^{15} 17$ in a third comparison, the published OR was approaching $50 \%$ of the univariate value. ${ }^{42}$

Two studies published ORs without raw data and therefore could not be included in the meta-analysis. Metsemakers et $a l^{69}$ reported on 486 tibial fractures using multiple linear regression smokers OR 1.74 (0.87 to 3.49$)$ for delayed union and 0.96 (0.48 to 1.95$)$ for non-union; however, in neither delayed or non-union was smoking considered to effect the odds statistically, $\mathrm{p}=0.120$ and 0.915 , respectively. We postulate that this could be due to the relatively young study population

Table 1 Comparison of published odds and risk ratios for included studies in comparison with the values generated through univariate meta-analysis

\begin{tabular}{|c|c|c|c|c|c|}
\hline Subgroup & Study & $\begin{array}{l}\text { Published } \\
\text { analysis }\end{array}$ & $\begin{array}{l}\text { Published OR } \\
\text { or RR }\end{array}$ & Meta-analysis RR & $\begin{array}{l}\text { Meta-analysis } \\
\text { OR }\end{array}$ \\
\hline \multirow[t]{3}{*}{ Fracture } & Enninghorst et $a l^{12}$ & Univariate & OR 2.26 (0.83 to 6.15$)$ & $1.71(0.91$ to 3.21$)$ & $2.26(0.83$ to 6.15$)$ \\
\hline & Ding et $a l^{15}$ & Multivariate & OR 5.34 (1.05 to 27.00$)$ & 2.53 (1.16 to 5.55$)$ & 2.64 (1.16 to 6.02$)$ \\
\hline & Liu et $a l^{17}$ & Multivariate & OR 4.16 (1.01 to 14.16$)$ & 1.90 (1.28 to 2.82$)$ & 2.12 (1.32 to 3.40$)$ \\
\hline Osteotomy & $\begin{array}{l}\text { W-Dahl and } \\
\text { Toksvig-Larsen } 26\end{array}$ & Multivariate & RR 2.7 (1.5 to 4.7 ) & 2.73 (1.59 to 4.69$)$ & 3.95 (1.77 to 8.83$)$ \\
\hline \multirow[t]{2}{*}{ Arthrodesis } & Chahal et $a \beta^{34}$ & Univariate & OR 3.87 (1.21 to 12.42$)$ & 3.09 (1.19 to 8.03$)$ & 4.06 (1.29 to 12.83$)$ \\
\hline & Ishikawa et a/33 & Univariate & $\mathrm{RR} 2.7$ & $2.63(1.02$ to 6.80$)$ & $3.00(1.01$ to 8.90$)$ \\
\hline \multirow{4}{*}{$\begin{array}{l}\text { Non-union } \\
\text { treatment }\end{array}$} & Chang et $a \beta^{\beta 9}$ & Univariate & OR 5.4 (1.3 to 22.13$)$ & 2.69 (1.17 to 6.19$)$ & $4.67(1.19$ to 18.35$)$ \\
\hline & Little et $a f^{40}$ & Univariate & RR 3.7 (1.3 to 10.1$)$ & 3.68 (1.35 to 10.09$)$ & 5.74 (1.61 to 20.40$)$ \\
\hline & Dinah and Vickers ${ }^{41}$ & Univariate & RR 3.4 & 3.40 (1.15 to 10.09$)$ & 7.00 (1.51 to 32.48$)$ \\
\hline & Murray et $a f^{12}$ & Multivariate & OR 3.76 (2.39 to 5.89 ) & 4.63 (3.35 to 6.39$)$ & 6.44 (4.33 to 9.59$)$ \\
\hline
\end{tabular}


(mean 30.2 years). Similarly, Egol et al $7^{0}$ presented an OR without suitable data for inclusion in the meta-analysis for long bone non-union in smokers 1.3 $(0.27$ to 6.40$)$ also stating a lack of significance ( $p>0.05)$.

\section{Time to union including limitations arising due to primary data}

The meta-analysis for the time to union was based on the mean time to union. This is not ideal when dealing with censorship when the union has not occurred during the study due to the length of follow-up. This was reported to have occurred with two patients in one study, where a value of 52 weeks was attributed at the final follow-up, despite healing not having occurred. ${ }^{44}$ This can be considered to have had a minimal influence in the total of 923 patients in the meta-analysis as censoring was not reported in any other study. An alternative approach to dealing with censoring in non-union data is survivorship modelling such as Kaplan-Meier estimates which provides an estimated median time to union. ${ }^{6}$ The Cox HRs have also been considered for discriminating between time to union in smokers and non-smokers. ${ }^{10}$

\section{Smoking cessation and advice to patients}

Perioperative smoking cessation is considered to be beneficial for fracture healing, although there are limited data to draw this conclusion. ${ }^{20} 2171$ As a large number of orthopaedic procedures are not elective, postoperative smoking is likely to play a more significant role in orthopaedic clinical practice. Andersen et al showed that fusion rate was higher in patients who gave up smoking postoperatively and Glassman et al observed a trend towards significance in those who gave up for longer than 6 months. ${ }^{20}{ }^{21}$ It has been suggested that the greater the number of cigarettes smoked, the longer the healing time. ${ }^{568}$ The question of how long a patient should abstain from smoking following injury is difficult to answer and may depend on how long a patient has been a smoker. In an animal model, smoking was observed to damage tibial endothelial cell function through nitric oxide production and marked vasospasm. Long-term exposure to smoke damaged the endothelium more severely than short-term exposure, and although the effects were reversible, cessation duration was linked to benefits. ${ }^{72}$

There should be clear advice to patients on smoking cessation at all clinic visits. Patients should be offered the opportunity to enrol into smoking cessation interventions. Smokers should be encouraged to abstain following a fracture, osteotomy or arthrodesis to maximise the chances of effective healing. With elective procedures, we suggest patients abstain for as long as possible, as much as 6 months preoperatively. We also suggest enrolling patients with high-risk injuries into cessation programmes that have been shown to achieve higher cessation rates. $^{73}$

\section{CONCLUSIONS}

This study shows that smokers take 27.7 days (14.2 to 41.3) longer for union to occur for fractures, osteotomy, arthrodesis and established non-union. Smokers have double the risk of non-union 2.2 (1.9 to 2.6) for fractures, osteotomy, arthrodesis and established non-union. It is important that this is explained at the same time as smoking cessation advice is given to orthopaedic patients preferably in good time, prior to elective orthopaedic surgery.

Contributors RGP, RGEC and BES conceived and designed the study and produced the search strategy. RGP and RGEC conducted the searches. RGP, RGEC, KLE and BES screened abstracts and titles, assessed study inclusion and exclusion, extracted data and assessed study quality. RGP, RGEC, KLE and $\mathrm{BES}$ were responsible for manuscript preparation and final approval of the manuscript.

\section{Competing interests None declared.}

Provenance and peer review Not commissioned; externally peer reviewed.

Data sharing statement No additional data are available.

Open Access This is an Open Access article distributed in accordance with the Creative Commons Attribution Non Commercial (CC BY-NC 4.0) license, which permits others to distribute, remix, adapt, build upon this work noncommercially, and license their derivative works on different terms, provided the original work is properly cited and the use is non-commercial. See: http:// creativecommons.org/licenses/by-nc/4.0/

\section{REFERENCES}

1. Donaldson LJ, Reckless IP, Scholes S. The epidemiology of fractures in England. J Epidemiol Community Health 2008;62:174-80.

2. Dahabreh Z, Dimitriou R, Giannoudis PV. Health economics: a cost analysis of treatment of persistent fracture non-unions using bone morphogenic protein-7. Injury 2006;38:371-7.

3. Gaston MS, Simpson AH. Inhibition of fracture healing. J Bone Joint Surg Br 2007;89:1553-60.

4. Lifestyles Statistics team, Centre HaSCl. Statistics on Smoking: England. 2015. http://www.hscic.gov.uk/catalogue/PUB17526/ stat-smok-eng-2015-rep.pdf

5. Kyro A, Usenius JP, Aarnio M, et al. Are smokers a risk group for delayed healing of tibial shaft fractures? Ann Chir Gynaecol 1993;82:254-62.

6. Schmitz MA, Finnegan M, Natarajan R, et al. Effect of smoking on tibial shaft fracture healing. Clin Orthop Relat Res 1999;365:184-200.

7. Adams $\mathrm{Cl}$, Keating JF, Court-Brown CM. Cigarette smoking and open tibial fractures. Injury 2001;32:61-5.

8. Harvey EJ, Agel J, Selznick HS, et al. Deleterious effect of smoking on healing of open tibia-shaft fractures. Am J Orthop (Belle Mead NJ) 2002;31:518-21.

9. McKee MD, DiPasquale DJ, Wild LM, et al. The effect of smoking on clinical outcome and complication rates following llizarov reconstruction. J Orthop Trauma 2003;17:663-7.

10. Castillo RC, Bosse MJ, MacKenzie EJ, et al. Impact of smoking on fracture healing and risk of complications in limb-threatening open tibia fractures. J Orthop Trauma 2005;19:151-7.

11. Ristiniemi J, Flinkkilä $T$, Hyvönen $P$, et al. Two-ring hybrid external fixation of distal tibial fractures: a review of 47 cases. $J$ Trauma 2007;62:174-83.

12. Enninghorst $\mathrm{N}$, McDougall $\mathrm{D}$, Hunt JJ, et al. Open tibia fractures: timely debridement leaves injury severity as the only determinant of poor outcome. J Trauma 2011;70:352-6.

13. Moghaddam A, Zimmermann G, Hammer K, et al. Cigarette smoking influences the clinical and occupational outcome of patients with tibial shaft fractures. Injury 2011;42:1435-42.

14. Ahmad MA, Sivaraman A, Zia A, et al. Percutaneous locking plates for fractures of the distal tibia: our experience and a review of the literature. J Trauma Acute Care Surg 2012;72:E81-7.

15. Ding $\mathrm{L}, \mathrm{He} \mathrm{ZM}$, Xiao $\mathrm{HJ}$, et al. Factors affecting the incidence of aseptic nonunion after surgical fixation of humeral diaphyseal fracture. J Orthop Sci 2014;19:973-7. 
16. Tay $\mathrm{WH}$, de Steiger $\mathrm{R}$, Richardson $\mathrm{M}$, et al. Health outcomes of delayed union and nonunion of femoral and tibial shaft fractures. Injury 2014;45:1653-8.

17. Liu W, Xiao J, Ji F, et al. Intrinsic and extrinsic risk factors for nonunion after nonoperative treatment of midshaft clavicle fractures. Orthop Traumatol Surg Res 2015;101:197-200.

18. Ruffolo MR, Gettys FK, Montijo HE et al. Complications of high-energy bicondylar tibial plateau fractures treated with dua plating through 2 incisions. J Orthop Trauma 2015;29:85-90.

19. Martin GJ Jr, Haid RW Jr, MacMillan M, et al. Anterior cervica discectomy with freeze-dried fibula allograft. Overview of 317 cases and literature review. Spine (Phila Pa 1976) 1999;24:852-8; discussion 58-9.

20. Glassman SD, Anagnost SC, Parker A, et al. The effect of cigarette smoking and smoking cessation on spinal fusion. Spine (Phila Pa 1976) 2000;25:2608-15

21. Andersen T, Christensen FB, Laursen M, et al. Smoking as a predictor of negative outcome in lumbar spinal fusion. Spine (Phila Pa 1976) 2001;26:2623-8.

22. Hilibrand AS, Fye MA, Emery SE, et al. Impact of smoking on the outcome of anterior cervical arthrodesis with interbody or strut-grafting. J Bone Joint Surg Am 2001;83-A:668-73.

23. Assiotis A, Sachinis NP, Chalidis BE. Pulsed electromagnetic fields for the treatment of tibial delayed unions and nonunions. A prospective clinical study and review of the literature. J Orthop Surg Res 2012;7:24.

24. Luszczyk M, Smith JS, Fischgrund JS, et al. Does smoking have an impact on fusion rate in single-level anterior cervical discectomy and fusion with allograft and rigid plate fixation? J Neurosurg Spine 2013;19:527-31.

25. Chen F, Osterman AL, Mahony K. Smoking and bony union after ulna-shortening osteotomy. Am J Orthop (Belle Mead NJ) 2001;30:486-9.

26. W-Dahl A, Toksvig-Larsen S. Cigarette smoking delays bone healing -a prospective study of 200 patients operated on by the hemicallotasis technique. Acta Orthop Scand 2004;75:347-51.

27. W-Dahl A, Toksvig-Larsen S. No delayed bone healing in Swedish male oral snuffers operated on by the hemicallotasis technique-a cohort study of 175 patients. Acta Orthop 2007;78:791-4.

28. Meidinger G, Imhoff AB, Paul J, et al. May smokers and overweight patients be treated with a medial open-wedge HTO? Risk factors for non-union. Knee Surg Sports Traumatol Arthrosc 2011;19:333-9.

29. van Houten $\mathrm{AH}$, Heesterbeek PJ, van Heerwaarden RJ, et al. Medial open wedge high tibial osteotomy: can delayed or nonunion be predicted? Clin Orthop 2014;472:1217-23

30. Bednarz PA, Beals TC, Manoli A. Subtalar distraction bone block fusion: an assessment of outcome. Foot Ankle Int 1997;18:785-91.

31. Perlman $\mathrm{MH}$, Thordarson DB. Ankle fusion in a high risk population: an assessment of nonunion risk factors. Foot Ankle Int 1999;20:491-6.

32. Easley ME, Trnka HJ, Schon LC, et al. Isolated subtalar arthrodesis. $J$ Bone Joint Surg Am 2000;82:613-24.

33. Ishikawa SN, Murphy GA, Richardson EG, et al. The effect of cigarette smoking on hindfoot fusions. Foot Ankle Int 2002;23:996-8.

34. Chahal J, Stephen DJG, Bulmer B, et al. Factors associated with outcome after subtalar arthrodesis. J Orthop Trauma 2006;20:555-61.

35. Collman DR, Kaas MH, Schuberth JM. Arthroscopic ankle arthrodesis: factors influencing union in 39 consecutive patients. Foot Ankle Int 2006;27:1079-85.

36. Hamilton GA, Mullins S, Schuberth JM, et al. Revision lapidus arthrodesis: rate of union in 17 cases. J Foot Ankle Surg 2007;46:447-50.

37. Fragomen AT, Borst E, Schachter L, et al. Complex ankle arthrodesis using the ilizarov method yields high rate of fusion foot and ankle. Clin Orthop Relat Res 2012;470:2864-73.

38. Hak DJ, Lee SS, Goulet JA. Success of exchange reamed intramedullary nailing for femoral shaft nonunion or delayed union. J Orthop Trauma 2000;14:178-82.

39. Chang MA, Bishop AT, Moran SL, et al. The outcomes and complications of 1,2-intercompartmental supraretinacular artery pedicled vascularized bone grafting of scaphoid nonunions. J Hand Surg Am 2006;31:387-96.

40. Little CP, Burston BJ, Hopkinson-Woolley J, et al. Failure of surgery for scaphoid non-union is associated with smoking. $J$ Hand Surg $\mathrm{Br}$ 2006;31:252-5.

41. Dinah AF, Vickers $\mathrm{RH}$. Smoking increases failure rate of operation for established non-union of the scaphoid bone. Int Orthop 2007;31:503-5.
42. Murray IR, Foster CJ, Eros A, et al. Risk factors for nonunion after nonoperative treatment of displaced midshaft fractures of the clavicle. J Bone Joint Surg Am 2013;95:1153-8.

43. Dujardyn J, Lammens J. Treatment of delayed union or non-union of the tibial shaft with partial fibulectomy and an llizarov frame. Acta Orthop Belg 2007;73:630-4.

44. Alemdaroglu KB, Tiftikçi U, Iltar S, et al. Factors affecting the fracture healing in treatment of tibial shaft fractures with circular external fixator. Injury 2009;40:1151-6.

45. AL-Hadithy N, Sewell MD, Bhavikatt M, et al. The effect of smoking on fracture healing and on various orthopaedic procedures. Acta Orthop Belg 2012;78:285-90.

46. Sloan A, Hussain I, Maqsood M, et al. The effects of smoking on fracture healing. Surgeon 2010;8:111-16.

47. Lee JJ, Patel R, Biermann JS, et al. The musculoskeletal effects of cigarette smoking. J Bone Joint Surg Am 2013;95:850-9.

48. Scolaro JA, Schenker ML, Yannascoli S, et al. Cigarette smoking increases complications following fracture: a systematic review. $J$ Bone Joint Surg Am 2014;96:674-81.

49. Bender D, Jefferson-Keil T, Biglari B, et al. Cigarette smoking and its impact on fracture healing. Trauma 2014;16:18-22.

50. Patel RA, Wilson RF, Patel PA, et al. The effect of smoking on bone healing: a systematic review. Bone Joint Res 2013;2:102-11.

51. Stroup DF, Berlin JA, Morton SC, et al. Meta-analysis of observational studies in epidemiology: a proposal for reporting. Meta-analysis Of Observational Studies in Epidemiology (MOOSE) group. JAMA 2000;283:2008-12.

52. Wells G, Shea B, O'Connell D, et al. The Newcastle-Ottawa Scale (NOS) for assessing the quality of nonrandomised studies in meta-analyses http://www.ohri.ca/programs/clinical_epidemiology/ oxford.asp (accessed Nov 2016).

53. Wenham CY, McDermott M, Conaghan PG. Biological therapies in osteoarthritis. Curr Pharm Des 2015;21:2206-15.

54. Brown CW, Orme TJ, Richardson HD. The rate of pseudarthrosis (surgical nonunion) in patients who are smokers and patients who are nonsmokers: a comparison study. Spine (Phila Pa 1976) 1986;11:942-3.

55. Ziran BH, Hendi $\mathrm{P}$, Smith WR, et al. Osseous healing with a composite of allograft and demineralized bone matrix: adverse effects of smoking. Am J Orthop (Belle Mead NJ) 2007;36:207-9

56. Cobb TK, Gabrielsen TA, Campbell DC II, et al. Cigarette smoking and nonunion after ankle arthrodesis. Foot Ankle Int 1994;15:64-7.

57. Hernigou J, Schuind F. Smoking as a predictor of negative outcome in diaphyseal fracture healing. Int Orthop 2013;37:883-7.

58. Taitsman LA, Lynch JR, Agel J, et al. Risk factors for femoral nonunion after femoral shaft fracture. J Trauma 2009;67:1389-92.

59. Giannoudis PV, MacDonald DA, Matthews SJ, et al. Nonunion of the femoral diaphysis - the influence of reaming and non-steroidal anti-inflammatory drugs. J Bone Joint Surg Br 2000;82:655-8.

60. Kanis JA, Borgstrom F, De Laet C, et al. Assessment of fracture risk Osteoporos Int 2005;16:581-9.

61. Kanis JA, Johnell O, Oden A, et al. FRAX (TM) and the assessment of fracture probability in men and women from the UK. Osteoporos Int 2008;19:385-97.

62. Karantana A, Boulton C, Bouliotis G, et al. Epidemiology and outcome of fracture of the hip in women aged 65 years and under a cohort study. J Bone Joint Surg Br 2011;93:658-64.

63. Lim SS, Vos T, Flaxman AD, et al. A comparative risk assessment of burden of disease and injury attributable to 67 risk factors and risk factor clusters in 21 regions, 1990-2010: a systematic analysis for the Global Burden of Disease Study 2010. Lancet 2012;380:2224-60.

64. Stewart CE, Hall IP, Parker SG, et al. PLAUR polymorphisms and lung function in UK smokers. BMC Med Genet 2009;10:112. doi:10.1186/ 1471-2350-10-112

65. Shahab L, Jarvis MJ, Britton J, et al. Prevalence, diagnosis and relation to tobacco dependence of chronic obstructive pulmonary disease in a nationally representative population sample. Thorax 2006;61:1043-7.

66. Venn A, Britton J. Exposure to secondhand smoke and biomarkers of cardiovascular disease risk in never-smoking adults. Circulation 2007:115:990-5.

67. Sheweita SA, Khoshhal KI. Calcium metabolism and oxidative stress in bone fractures: role of antioxidants. Curr Drug Metab 2007;8:519-25.

68. Krannitz KW, Fong HW, Fallat LM, et al. The effect of cigarette smoking on radiographic bone healing after elective foot surgery. $J$ Foot Ankle Surg 2009:48:525-7.

69. Metsemakers WJ, Handojo K, Reynders P, et al. Individual risk factors for deep infection and compromised fracture healing after intramedullary nailing of tibial shaft fractures: a single centre experience of 480 patients. Injury 2015;46:740-5. 
70. Egol KA, Bechtel C, Spitzer AB, et al. Treatment of long bone nonunions: factors affecting healing. Bull NYU Hosp Jt Dis 2012;70:224-31.

71. Nåsell $\mathrm{H}$, Adami J, Samnegård $\mathrm{E}$, et al. Effect of smoking cessation intervention on results of acute fracture surgery: a randomized controlled trial. J Bone Joint Surg Am 2010;92:1335-42.
72. Yen $\mathrm{CY}, \mathrm{Tu} \mathrm{Yk}, \mathrm{Ma} \mathrm{CH}$, et al. Measurement of tibial endothelial cell function after cigarette smoking, cessation of smoking and hyperbaric oxygen therapy. Injury 2008;39(Suppl 4):40-6.

73. Coleman T. Cessation interventions in routine health care. BMJ 2004;328:631-3. 